\title{
VULNERABILIDADES DE SISTEMAS CIBER FÍSICOS
}

\author{
João Paulo Pimentel, Matheus Santos Monteiro, Francisco Lopes de Caldas Filho, \\ Fábio L. L. Mendonça, Awatef Ali Yousef R Fares e Rafael T. de Sousa Júnior \\ Programa de Pós-Graduação Profissional em Engenharia Elétrica (PPEE), Departamento de Engenharia Elétrica, \\ Universidade de Brasília, Brasília, Brasil, Zipcode 70910-900
}

\begin{abstract}
RESUMO
A primeira transmissão de rádio frequência foi no ano de 1892 e desde então essa tecnologia vem evoluindo com o passar dos anos. Uma das áreas que usam o RF (Radiofrequência) é na parte de segurança privada com o dispositivo emissor/receptor $433 \mathrm{MHz}$, que é usado em portões eletrônicos de residências particulares e empresas. No entanto, esta tecnologia apresenta falha de segurança de dados no envio do seu sinal, desta forma, deixando esta tecnologia vulnerável a ataques. Este artigo visa produzir um dispositivo IoT que explore essa vulnerabilidade, a fim de demonstrar a sua insegurança.
\end{abstract}

\section{PALAVRAS-CHAVE}

$433 \mathrm{MHz}$, IoT, RF, Vulnerabilidade, Segurança

\section{INTRODUÇÃO}

As comunicações sem fios é uma tecnologia que a cada dia mais é utilizada para envio e recebimento de informação (Gupta, et al., 2000). A sua criação se deu no ano de 1892 com o pesquisador e cientista padre Roberto Landell de Moura com a primeira transmissão de RF (Radiofrequência) com o alcance de $8 \mathrm{Km}$ (Alencar, et al., 2004). Assim, com o passar dos anos os seus métodos e protocolos de envio a partir de RF evoluíram até chegar nos tempos de hoje com diferentes uma variedade de tecnologias como: Wi-fi, Bluetooth, BTLE, ZigBee, Z-Wave e entre outros.

Segundo (Waslon TA, et al., 2016) RF é qualquer frequência de ondas eletromagnéticas na faixa de 3 $\mathrm{KHz}$ a $300 \mathrm{GHz}$ que são geradas por oscilações elétricas. Assim, para enviar e receber informações são necessários dois dispositivos um transmissor e outro receptor. O receptor codifica e envia o sinal em determinada frequência e o receptor recebe esse sinal e o decodifica.

Um dos modelos de dispositivos RF, mais usados na parte de segurança particular, é o emissor e receptor de RF $433 \mathrm{MHz}$, essa tecnologia sem fio é utilizada em motores portões eletrônicos domiciliares e empresariais. O módulo transmissor/receptor RF 433 tem uma frequência de $433 \mathrm{MHz}$ que a sua transmissão ocorre com uma taxa de 1 Kbps a 10 Kbps (Kuno, et al., 1999).

No entanto, a transmissão de sinal RF $433 \mathrm{MHz}$ apresenta vulnerabilidade de segurança (Kahil, et al., 2017), assim comprometendo a proteção dos locais onde utilizam essa tecnologia.

Segundo a (Anon., s.d.) Eletrônica o mercado de segurança eletrônica brasileiro faturou 7,17 bilhões de reais no ano de 2019 e para o ano de 2020 tem uma previsão de um crescimento de $12 \%$.

Desta Forma, mais pessoas físicas e jurídicas vão utilizar motor de portão eletrônico em suas casas, empresas e condomínios. Por garantir comodidade e permitir a abertura e fechamento remoto, reduzindo o tempo de exposição do motorista fora dos limites da residência. Este dispositivo, entretanto, apresenta falhas de segurança que se utilizadas, podem permitir que pessoas não autorizadas tenham acesso ao ambiente que deveria ser restrito apenas a pessoas que tenham posse do controle corretamente codificado do portão.

Visando a melhoria da segurança eletrônica mais especificamente o motor dos portões eletrônicos, este artigo tem como objetivo apresentar um protótipo de dispositivo de segurança capaz de aproveitar da vulnerabilidade dos sistemas de portão eletrônico, como interceptar o código de um portão por um dispositivo próximo, possibilitando que um invasor abra o portão sem autorização do proprietário da casa. Com o advento dos dispositivos e tecnologias de IoT (Internet of Things), essas vulnerabilidades podem ser exploradas ainda mais longe, permitindo que o código do portão seja enviado para terceiros pela internet, além de comandar a abertura do portão a distância. 


\section{TRABALHOS RELACIONADOS}

Muitos métodos de provar a vulnerabilidade do RF $433 \mathrm{MHz}$ já foram propostos, tendo por objetivo de explicitar a insegurança dessa tecnologia.

Em (Azevedo, 2019) foi proposto um sistema que explora vulnerabilidades de transmissores e receptores que operam frequência de $433 \mathrm{MHz}$. Utilizando dois microcontroladores, um transmissor e um receptor 433 $\mathrm{MHz}$ e um computador. O sinal codificado enviados pelo controle do portão eletrônico é copiado pelo receptor $433 \mathrm{MHz}$ e em seguida mostrado os seus parâmetros - frequência, largura de pulso e protocolo - na serial da IDE do Arduino. Posteriormente, usando esses parâmetros, um emissor $433 \mathrm{MHz}$ e uma microcontrolador é simulado o sinal de RF para abrir o portão. No entanto, essa solução é pouco prática e requer um notebook para poder ver os resultados obtidos, diferentemente proposto nesse artigo que visa fazer isso tudo em apenas um dispositivo IoT sem a utilização de um computador.

Enquanto no artigo (Hung, et al., 2019) foi proposto um sistema que utiliza apenas um microcontrolador, o transmissor RF $433 \mathrm{MHz}$, receptor RF $433 \mathrm{MHz}$ e led's. Com o intuito de poder captar qualquer sinal de de transmissão de $433 \mathrm{MHz}$, no entanto a solução não apresenta controle sem fio, fazendo apenas a citação que possui autonomia mas não demonstra no artigo, deste modo será necessário o uso de um computador para analisar o sinal interceptado e enviado o dado, desta forma limitando o uso do dispositivo. No entanto, este artigo visa construir um dispositivo autônomo sem a utilização de um computador para analisar os dados obtidos.

Porém no artigo (Fernández \& Rodrigo, 2018) foi feito um sistema com dois dispositivos uma para a recebimento do sinal RF $433 \mathrm{MHz}$ utilizando um microcontrolador e um receptor RF $433 \mathrm{MHz}$ e outro para enviar o sinal que utiliza um microcontrolador e um emissor RF $433 \mathrm{MHz}$, a fim de melhorar a segurança do sinal RF $433 \mathrm{MHz}$ a partir de criptografia, assim protegendo os sinais enviados, mas o artigo proposto neste trabalho visa aproveitar a vulnerabilidade de dispositivo com um dispositivo único e autônomo, sem a necessidade de dois microcontroladores.

De forma similar, o artigo (Hussein, et al., 2017) tem como fim melhorar a segurança das tags e leitores de RFID, utilizando um dispositivo que possui um sistema com um microcontrolador e receptor e emissor de sinal RF $433 \mathrm{MHz}$. Assim, utilizando um protocolo de autenticação mútua entre os leitores de RFID e as tags. Desta forma, mantendo as tags e os RFID's protegidos de qualquer ataque de invasores, no entanto este artigo proposto tem como objetivo explorar essa vulnerabilidade do sinal RF $433 \mathrm{MHz}$.

Por outro lado, o artigo (Rasmussen, et al., 2007) utilizando o sensor Chipcon 1000 rádio, 433MHz, este demonstra que um receptor pode criar impressões digitais de rádio do dispositivo e depois identificar a proveniência das mensagens enviadas de um dispositivo ao outro, mesmo que as mensagens estejam ocultas. No entanto, o método de captura do sinal é analógico, então para converter esse sinal para um sinal digital é necessário um osciloscópio. Desta forma deixando essa solução complicada e com muitos processos. Em contra partida, a solução proposta nesse artigo tem como objetivo realizar receptações utilizando um dispositivo microcontrolado e de fácil manuseio, assim facilitando a replicação dessa solução.

\section{ARQUITETURA PROPOSTA}

Tomando como base os projetos mencionados nos trabalhos relacionados, foi desenvolvido, nesse artigo, um dispositivo que intercepta o sinal RF $433 \mathrm{MHz}$, não criptografado, de controles de portão eletrônico. Em seguida, esse sinal é gravado na memória do microcontrolador e depois é enviado os parâmetros do sinal capturado para um Bot do Telegram utilizando redes sem fio 802.11n. A figura 1 demonstra a arquitetura proposta desse Projeto IoT.

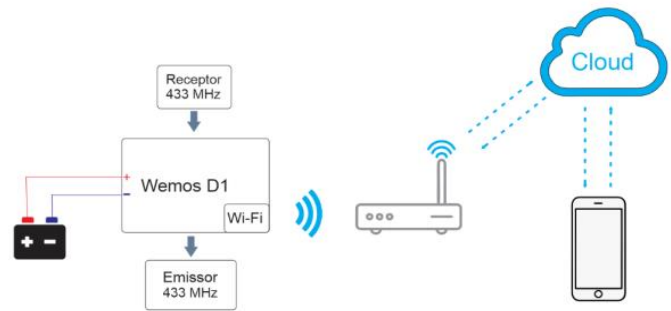

Figura 1. Arquitetura proposta 


\subsection{Hardware}

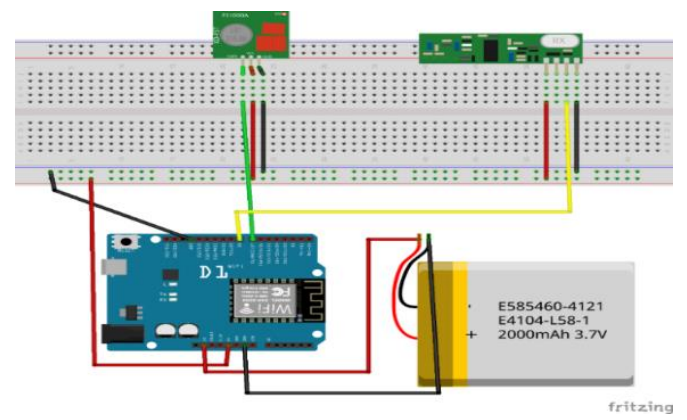

Figura 2. Hardware da Arquitetura Proposta

A figura 2 demonstra o hardware da arquitetura proposta utilizando o software Freezing.

O dispositivo proposto possui um microcontrolador Wemos D1 Wifi ESP8266 que é o módulo mais utilizado para aplicações em IoT por ser de baixo custo e baixo consumo de energia, pois a sua potência é de 3.3 Volts e o seu módulo Wi-Fi possui o protocolo TCP/IP integrado, assim pode-se usar aplicações webs como o chatbot do Telegram (Kodali, et al., 2016 ). Também foi utilizado uma protoboard, o módulos RF $433 \mathrm{MHz}$ que é formado por dois segmentos: o receptor, que é incumbido de captar os sinais de frequência $433 \mathrm{MHz}$, ele trabalha com uma tensão de 5 Volts e corrente de $4 \mathrm{~mA}$ com uma sensibilidade de $-105 \mathrm{~dB}$, e o transmissor, que é encarregado de emitir o sinal de frequência $433 \mathrm{MHz}$, ele trabalha com a tensão de 3.5 a 12 volts, com um raio de alcance de 20 a 200 metros e transmite dados com uma velocidade de 4 Kbps (Marcos \& Lucas, 2018). Uma bateria, de preferência, 3,7v para alimentar o circuito e dar mobilidade ao dispositivo e por último uma antena para o emissor RF $433 \mathrm{MHz}$ para poder melhorar a distância do envio do sinal (Alves, 2018).

\subsection{Software}

Utilizando a IDE do Arduíno, que é um Ambiente de Desenvolvimento Integrado que serve para editar, compilar e fazer upload de códigos em microcontroladores (Fezari, et al., 2018), e as bibliotecas (Özgür, 2019), (Stefano, s.d.) e (Arduino, s.d.), foi criado uma API que captura os parâmetros de frequência, comprimento do pulso e protocolo do controle interceptado que segundo (Özgür, 2019) pode ser 5 tipos, posteriormente envia os parâmetros para Telegram, que é um aplicativo de mensagens para smartphones que enviar e receber texto e mensagens multimídias (de, et al., 2016). no qual possui uma função chatbot que é um usuário controlado por um microcontrolador que a partir de um programa pode-se simula um usuário humano (Org, s.d.), essa função foi utilizada para diminuir o uso de periféricos no hardware e ter uma automação digital IoT.

E por fim, o sinal capturado pode ser simulado pelo microcontrolador a partir de um comando "/Play" do Telegram Bot assinado pelo smartphone como mostrada na figura 3.

Ao ser acionado, o microcontrolador busca na memória EEPROM, que consiste na memória não volátil do dispositivo (Harari, et al., 1994), os parâmetros do controle copiado a fim de utilizar esse sinal para poder abrir o portão eletrônico referente ao controle com o sinal copiado.

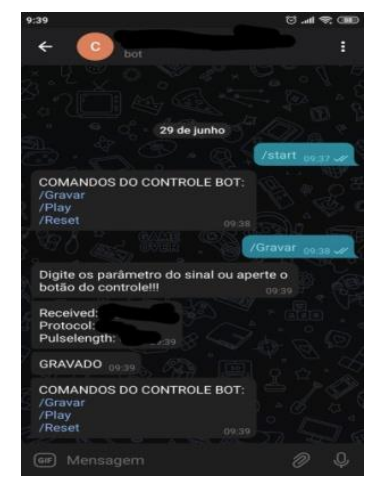

Figura 3. Interface do Bot do Telegram 


\section{RESULTADOS}

O objetivo deste artigo é mostrar vulnerabilidade dos emissores de RF $433 \mathrm{MHz}$ a partir de um dispositivo IoT via comandos Telegram bot. Desta forma, foram realizados dois tipos de testes, primeiro foi quanto à distância máxima de envio e recepção de dados e o segundo quanto à eficácia na clonagem dos sinais de RF $433 \mathrm{Mhz}$ em ambientes controlados e com a autorização dos proprietários das residências. Primeiramente foi realizado testes quanto à distância máxima que receptor $433 \mathrm{MHz}$ intercepta o sinal do controle do portão eletrônico. Foram utilizados 3 modelos de averiguação, no modelo 1 o receptor não possui antena, no modelo 2, o receptor possui uma antena senoidal de tamanho $2,5 \mathrm{~cm}$ e por último, no modelo 3 , o receptor possui uma antena de tamanho $40 \mathrm{~cm}$. Pode-se observa que o receptor $433 \mathrm{MHz}$ consegue interceptar a uma distancia de 7,66 metros sem a antena, 11,4 metros com a antena senoidal de 2,5 cm e 18,5 metros com a antena de $40 \mathrm{~cm}$ sem anteparos. A tabela 1 demonstra os resultados dos testes de cada modelo.

Tabela 1. Resultados dos testes de distância de interceptação de sinal do receptor $433 \mathrm{MHz}$

\begin{tabular}{|c|c|}
\hline Modelos & Distância máxima (M) \\
\hline modelo 1 & $\mathbf{7 , 6 6}$ \\
\hline modelo 2 & $\mathbf{1 1 , 4}$ \\
\hline modelo 3 & $\mathbf{1 8 , 5}$ \\
\hline
\end{tabular}

Em seguida, foi feito a distância máxima do envio do sinal copiado com o emissor $433 \mathrm{MHz}$. Foi usado apenas um modelo com o emissor com a antena senoidal de $2,5 \mathrm{~cm}$ e nos testes deu que a distância máxima foi de +/- 20 metros sem anteparo.

Por último foram realizados testes amostrais com 15 controles eletrônicos, 5 motores de portões eletrônicos de 4 casas diferentes para mostrar a vulnerabilidade desses sistemas, onde foi possível copiar o sinal de 5 controles para verificar a eficácia do dispositivo. Para os controles que foram possíveis fazer a cópia, conseguiu abrir o portão de duas casas. No entanto, não foi possível copiar o sinal de 11 controles, pelo o fato desses controles ser criptografados com a tecnologia Rolling code.

A criptografia Rolling code consiste em um sistema de transmissão segura de RF, com um código fixo e um código rotativo de bit trinário intercalado (Farris, et al., 2000).

\section{CONCLUSÃO E TRABALHOS FUTUROS}

Em suma, foi construído um dispositivo IoT que consegue copiar, à distância, um sinal de controle remoto que trabalham com tecnologia de RF $433 \mathrm{MHz}$ para abrir portão eletrônico, depois esse dispositivo grava na memória e enviar via Telegram bot para um celular previamente cadastrado, sendo que os códigos estão sob sigilo, para evitar quebra da propriedade intelectual. Deste modo este disposto aproveita a vulnerabilidade dessa tecnologia tão comum em residências e empresas.

Os testes foram realizados em ambientes controlados e em residências autorizadas pelo os seus proprietários, desta forma com base nos testes e nos dados obtidos, que não foram mostrados pelo o fato de ser dados sigilosos, é possível afirmar que o projeto alcançou a maioria dos objetivos propostos, dado que usando o Telegram bot e o dispositivo criado, foi possível capturar, gravar na memória e enviar no Telegram o sinal emitido por alguns controles eletrônicos e com este mesmo sinal, foi possível simular uma controle eletrônico e abrir portões eletrônicos de duas residências, dessa maneira demonstrando a vulnerabilidade de alguns dispositivos que utiliza sinal RF $433 \mathrm{MHz}$, porém alguns controles eletrônicos não foi possível de capturar o sinal, devido ao sistema de criptografia Rolling code.

Como Trabalhos futuros, pode ser realizado um sistema digital de portão eletrônico a partir de chatbot Telegram para melhorar o sistema de segurança dos portões eletrônicos. 


\section{AGRADECIMENTOS}

Os autores agradecem o apoio das Agências brasileiras de pesquisa, desenvolvimento e inovação CNPq (Projetos INCT SegCiber 465741/2014-2, PQ-2 312180/2019-5 e LargEWiN BRICS2017-591), CAPES (Projetos FORTE 23038.007604/2014-69 e PROBRAL 88887.144009/2017-00) e FAPDF (Projetos UIoT 0193.001366/2016 e SSDDC 0193. 001365/2016), bem como o suporte do Laboratório LATITUDE/UnB (Projeto SDN 23106. 099441/2016-43), a cooperação com o Ministério da Economia (TEDs DIPLA 005/2016 e ENAP 083/2016), o Gabinete de Segurança Institucional da Presidência da República (TED 002/2017), a Advocacia-Geral da União (TED 697.935/2019) e o Conselho Administrativo de Defesa Econômica (TED 08700.000047/2019-14).

\section{REFERÊNCIAS}

Alves, S. I., 2018. Semáforo inteligente para veículos de emergência.. s.1.:s.n.

A., M. S. a. A., T. T. a. L. \& W. T., 2004. What Father Landell de Moura Used to Do in His Spare Time. Proceeding of the IEEE Transactions on the History of Electronics.

Anon., s.d. Mercado de segurança eletrônica no Brasil faturou $R \backslash \$ 7,17$ bilhões em 2019. [Online] Available at: https://revistasegurancaeletronica.com.br/mercado-de-seguranca-eletronica-no-brasil-faturou-r-717bilhoes-em-2019-previsao-e-de-crescimento-de-12-em-2020/[Acesso em 10 Julho 2020].

Arduino, s.d. EEPROM Library. [Online] Available at: https://www.arduino.cc/en/Reference/EEPROM

Azevedo, R. O. S. d., 2019. Sistema de gerenciamento remoto de dispositivos de Internet das Coisas protegidos por Rede Virtual Privada. s.1.:s.n.

d. O., J. C. a. S., D. H. a. N. \& M. P., 2016. Chatting with arduino platform through telegram bot. Em: 2016 IEEE International Symposium on Consumer Electronics (ISCE). s.1.:s.n., pp. 131-132.

F., B. L. a. F. \& J. J., 2000. Rolling code security system. Estados Unidos da América, Patente No 6,154,544.

F., M. a. A. D. \& A., 2018. Integrated Development Environment “IDE” For Arduino. WSN applications, pp. 1-12.

F. \& R. J., 2018. Securización de Sistema de Mando a Distancia con RF Rodrigo. s.1., s.n.

Gupta, P. a. K. \& P. R., 2000. The capacity of wireless networks. IEEE Transactions on information theory, 46(2), pp. 388-404.

H., E. a. N., R. D. a. M. \& S., 1994. Flash eeprom system. s.l. Patente No 5,297,148.

H., I. A. a. A., R. S. a. J. \& B. H., 2017. Design and Implementation of RFID Active Tags and Mutual Authentication Protocol with Ownership Transfer Stage. Iraqi Journal for Electrical And Electronic Engineering, 13(1), pp. 83-103.

H., P. D. a. V. \& B. T., 2019. Vulnerabilities in IoT Devices with Software-defined radio. Em: 2019 IEEE 4th International Conference on Computer and Communication Systems (ICCCS). s.1.:IEEE, pp. 664-668.

K. et al., 2017. Innovation of a secured transmitter/receiver chain by creating a new encryption algorithm. Em: 2017 Sensors Networks Smart and Emerging Technologies (SENSET). s.l.:s.n., pp. 1-3.

K., R. K. a. M. \& K. S., 2016. A low cost implementation of MQTT using ESP8266. Em: 2016 2nd International Conference on Contemporary Computing and Informatics (IC3I). s.l.:s.n., pp. 404-408.

K. et al., 1999. Robotic wheelchair with three control modes. Em: Proceedings 1999 IEEE International Conference on Robotics and Automation (Cat. No. 99CH36288C). s.1.:s.n., pp. 2590-2595.

M. V. C. d. L. O. \& L. H., 2018. Sistema de comunicação de dados utilizando Arduino e Módulo RF 433 MHZ. s.1.:s.n.

Org, T., s.d. Telegram Bot. [Online] Available at: https://telegram.org/blog/bot-revolution

Özgür, S., 2019. Arduino libary for remote control outlet switches. [Online] Available at: https://github.com/sui77/rcswitch/

R., K. B. e. C. \& S., 2007. Implications of radio fingerprinting on the security of sensor networks. Em: 2007 Third International Conference on Security and Privacy in Communications Networks and the Workshops-SecureComm 2007. s.1.:s.n., pp. 331-340.

S. L., s.d. Simple Arduino Telegram BOT library for ESP8266. [Online] Available at: https://github.com/shurillu/CTBot

W. T. et al., 2016. $433 \mathrm{MHz}$ (Wireless RF) communication between two Arduino UNO. American Journal of Engineering Research (AJER), 5(10), pp. 358-362. 